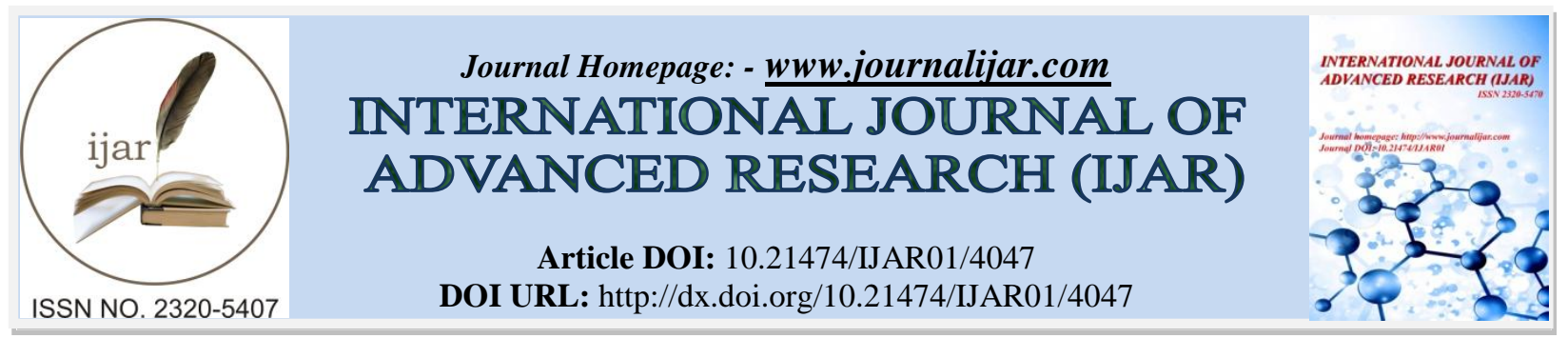

RESEARCH ARTICLE

\title{
ORAL MICROBIOTA OF NEW BORN INFANT OF CAESAREAN \& VAGINAL DELIVERIES: A COMPARATIVE MICROBIOLOGICAL STUDY.
}

\section{Dr. Manvi Srivastava ${ }^{1}$, Dr. Updesh Masih $^{2}$, Dr. Gurpreet Kour ${ }^{3}$, Dr. Meenu Saini ${ }^{4}$ and Dr. Kanupriya Rathore 5 .}

1. MDS, Senior Lecturer, Department of Pedodontics and Preventive Dentistry, K.D. Dental College \& Hospital, Mathura, India.

2. MDS, Professor, Department of Pedodontics and Preventive Dentistry, K.D. Dental College \& Hospital, Mathura, India.

3. MDS, Department of Pedodontics and Preventive Dentistry, K.D. Dental College \& Hospital, Mathura, India

4. MDS, Department of Pedodontics and Preventive Dentistry, K.D. Dental College \& Hospital, Mathura, India

5. MDS, Senior Lecturer, Department of Pedodontics and Preventive Dentistry, Jodhpur Dental College \& Hospital, Jodhpur, India.

\section{Manuscript Info}

\section{Manuscript History}

Received: 22 February 2017

Final Accepted: 26 March 2017

Published: April 2017

Key words:-

Normal delivery, Cesarean delivery, Microflora, First feeding

\section{Abstract}

Aim:- To investigate the correlation between the bacterial flora of vagina of the mother and the oral cavity of the newborn and to determine the difference in the oral microflora of a newborn with normal and cesarean delivery immediately after birth and after feeding. Methodology:- The study was conducted on 50 expectant mothers. The samples were collected from the 2 Registered Private Maternity Hospitals in Mathura City. The subjects were informed and explained about the procedure and a written consent was obtained. The samples were collected from 25 newborns by normal delivery and 25 by cesarean delivery. Three swabs were taken from the subjects i.e., one from maternal birth canal and 2 from the oral cavity of newborn immediately after birth and after first feeding. Samples were sent to the laboratory under sterile condition, for the microbiological assessment.

Results: In this study it was observed that the oral cavity of newborns was found to be sterile in $40 \%$ of normal delivery and $76 \%$ through caesarean delivery.

Conclusion:- The mode of delivery has an influence on the salivary microbial profile in infants. Streptococcus salivarius was established into the oral cavity only after the first feeding.

Copy Right, IJAR, 2017,. All rights reserved.

\section{Background:-}

Myriads of micro organisms abound in the world. These single cell creatures represent the major diversity of life on our planet. Micro organisms not only constitute the communal but also the normal microflora of the human body. The human body, consisting of about 100 trillion cells, carries about ten times as many microorganisms in the intestines. ${ }^{1}$ The healthy human fetus is thought to develop in a bacteria free environment. It was previously hypothesized that the oral cavity of the new born is sterile at the time of birth and the colonization starts after the neonate is exposed to the environment. 
But studies have shown that upon delivery the neonate get exposed to a wide variety of microbes which are provided by the mother during and after passage through the birth canal. ${ }^{2,3,4,5}$ These micro organisms participate in the initial building of the oral ecosystem and also produce changes in the long term colonization of oral microbiota as well as subsequent alteration in the immune development of the new born. ${ }^{6}$

Hence the aim of this study was to investigate whether there is a correlation between the bacterial flora of vagina or amniotic fluid of the mother and the oral cavity of the newborn and also to determine the difference in the oral microflora of a newborn with normal delivery and cesarean delivery immediately after birth and after feeding.

\section{Methodology:-}

Before the commencement of this study the clearance was taken from the ethical committee board of K.D. Dental College \& Hospital, Mathura. The samples were collected from the 2 Registered Private Maternity Hospitals. The participants of the study were explained about the procedure and informed written consent was obtained. This study was conducted on 50 newborns and their mothers. Information on the past medical and pregnancy history was taken from the mother. Mothers with the history of recent antibiotic usage, viral and systemic diseases were excluded from this study.

Prior to the delivery, swabs were taken from the mother's birth canal using a sterile cotton swab. Immediately following the birth \& 2 hours after the first feeding, swabs were taken from the oral cavity (tongue \& buccal musosa) of the newborn. All the samples were collected aseptically in duplicate with sterile swabs and transported to laboratory at the earliest.

The swabs were inoculated in tryptose soya broth(TSB) and incubated at $37^{\circ} \mathrm{C}$ for 24 hours at two different conditions. One set was incubated in ordinary incubator while second set was incubated under $5 \% \mathrm{CO}_{2}$ tension in desiccators for the isolation of microaerophilic as well as facultative anaerobic bacteria pathogens.

After incubation the broth showing the turbidity were transferred on Tryptose soya agar medium culture plates with the help of sterile bacteriological loop and further incubated at two different incubation conditions viz., aerobic and $5 \% \mathrm{CO}_{2}$. The glass slides with the smear were stained with Gram's stain and microscopically observed for organism morphology. The specimens inoculated in the Tryptose soya agar were then placed in the incubator for 18-24 hours and then inoculated into the blood agar and McConkey media, using a sterile inoculating loop. The media were incubated for 18-24 hours. After 24 hours, the culture media were observed for growth. If no growth was evident, it was further incubated. Colonies from the growth were observed, to study colony morphology. The colonies were further processed for sub-culture. A further biochemical reaction was performed to confirm the identity of the organisms. McNemar \& Pearson Chi Square test were utilized to compare the data obtained. Thus, a p-value $<0.05$ was considered statistically significant to account for multiple comparisons.

\section{Results:-}

The micro organisms isolated from the birth canal of the mother included S. epidermidis, S. aureus, Lactobacillus, Kleibsella, Neisseria, P. aeroginosa, Candida albicans, Gardenella sp., E. coli and Micrococcus.

Table 1 shows the highly significant difference in the levels of Lactobacillus and Candida albicans from the mother to child in normal delivery. When comparing the sterile conditions of oral cavity immediately and 2 hours after feeding the difference was found to be highly significant. (Table 2)

On comparison of vaginal microflora of mothers with the microflora of newborn of C- section, a significant difference was observed in the levels of S. epidermidis and Lactobacillus. (Table 3)

Counts of micro organisms were also found to vary in subsequent follow up and the micro organisms which were not present at the time of birth were observed to colonize the oral cavity after the feeding. $($ Table 2, 4)

The microbial load was found to be lower in cases of newborn immediately after the delivery in the oral cavity of newborns delivered through caesarean delivery. (Table 5)

Table 6 shows no statistically significant difference when intergroup comparison was done 2 hours after the feeding. 


\section{Discussion:-}

During birth and rapidly thereafter, bacteria from the mother and the surrounding environment colonize the infant's oral cavity. Hence it is seen that the oral cavity is not sterile at the time of the birth which is also indicated by the various studies. $2,7,8$

In this study it was observed that the oral cavity of newborns was found to be sterile in $40 \%$ of normal delivery and $76 \%$ through caesarean delivery. Witkowski (1935), Panesar J. (1997), Hegde S (1998) reported that the oral cavity of the infants were sterile in $2 \%, 12 \%$ and $6 \%$ respectively through normal delivery.

Reddy S (2010) ${ }^{9}$ in their study observed that the oral cavity of infants through normal delivery was sterile in $20 \%$ whereas through caesarean delivery it was $44 \%$. The difference in the sterile condition of the oral cavity of the infants could be because of all the aseptic precautions taken while conducting this study.

Despite of all the asepsis done, none of the birth canal was found to be sterile. Majority of the micro organisms present at the time of delivery constituted the normal vaginal microflora. In this study, the microorganisms found in mother's birth canal were Staphylococcus epidermidis, Staphylococcus aureus, Lactobacillus, Klebsiella sp., Neisseria sp., Pseudomonas aeroginosa, Candida albicans, Gardnerella sp., E. coli \& Micrococcus, among which S. epidermidis and S. aureus are the normal habitat of the human skin. It was also seen that these two micro organisms does not co- exist at a particular time in the birth canal and the oral cavity.

Similar micro organisms were also found in the oral cavity of the newborn delivered via normal delivery. This suggests that the mother's birth canal could have been the source for these microorganisms for the child. A similar finding was reported by Tones-Alipi (1990) ${ }^{10} \&$ Dominguez-Bello (2010) ${ }^{11}$. The degree of contamination of the newborn is significantly correlated with the microorganisms found in the mother's birth canal. Mandar R. $(1996)^{12}$ also observed similar findings.

On the other hand, infants delivered via Caesarean delivery harbored microbial communities like Staphylococcus epidermidis, Candida that were most likely to be transferred from the skin of parents, health providers and medical equipments.

The other samples which were taken 2 hours after the feeding, from the oral cavity of the newborns showed a major difference in the microbial colonies of Staphylococcus epidermidis. The bacterium which was not present at the time of birth and was developed after the first feeding was Streptococcus salivarius which is also the initial colonizer of the human oral cavity. Similar results were found by Hegde S (1998) in their study.

\section{Conclusion:-}

\section{The following conclusions could be drawn from this study:-}

Oral cavity was found to be sterile in $40 \%$ and $76 \%$ in the newborn through Normal and Caesarean delivery respectively. The mode of delivery has an influence on the salivary microbial profile in infants. Regardless of the type of delivery, the mothers' birth canal was contaminated.

The oral cavity of the newborn may get contaminated with the microorganisms from any of three sources - by contamination from the birth canal or hospital infection or contaminated instruments. Streptococcus salivarius was established into the oral cavity only after the first feeding.

Table I:- Comparison of the levels of micro organisms in the mothers and newborns at the time of delivery (Normal)

\begin{tabular}{|l|l|l|l|}
\hline & Mother (25) & Immediately after birth (25) & p-value (Mc Nemar Test) \\
\hline Sterile & - & 10 & NA \\
\hline Staphylococcus epidermidis & 20 & 15 & 0.062 \\
\hline Staphylococcus aureus & 5 & 0 & 0.063 \\
\hline Streptococcus salivarius & - & - & NA \\
\hline Lactobacillus & 23 & 6 & $<\mathbf{0 . 0 0 1}$ \\
\hline Klebsiella sp. & 11 & 7 & 0.125 \\
\hline Neisseria sp. & 4 & 9 & 0.062 \\
\hline
\end{tabular}




\begin{tabular}{|l|l|l|l|}
\hline Pseudomonas aeroginosa & 9 & 2 & 0.016 \\
\hline Candida albicans & 15 & 4 & $\mathbf{0 . 0 0 1}$ \\
\hline Gardnerella sp. & 10 & 6 & 0.125 \\
\hline E. coli & 11 & 4 & 0.016 \\
\hline Micrococcus & 3 & 1 & 0.500 \\
\hline
\end{tabular}

Table II:- Intra group comparison of microbial load in oral cavity of newborn through normal delivery

\begin{tabular}{|c|c|c|c|}
\hline Bacteria & Immediately after birth & 2 Hours after feeding & $\begin{array}{l}\text { Immediate v/s After } 2 \text { hrs } \\
\text { p-value }\end{array}$ \\
\hline Sterile & 10 & 2 & 0.004 \\
\hline $\begin{array}{l}\text { Staphylococcus } \\
\text { epidermidis }\end{array}$ & 15 & 21 & 0.016 \\
\hline Staphylococcus aureus & - & - & NA \\
\hline Streptococcus salivarius & - & 6 & NA \\
\hline Lactobacillus & 6 & 9 & 0.125 \\
\hline Klebsiella sp. & 7 & 3 & 0.125 \\
\hline Neisseria sp. & 9 & 4 & 0.062 \\
\hline Pseudomonas aeroginosa & 2 & - & NA \\
\hline Candida albicans & 4 & 1 & 0.250 \\
\hline Gardnerella sp. & 6 & - & NA \\
\hline E. coli & 4 & 1 & 0.250 \\
\hline Micrococcus & 1 & - & NA \\
\hline
\end{tabular}

Table III:- Comparison of the levels of micro organisms in the mothers and newborns at the time of delivery (Caesarean)

\begin{tabular}{|c|c|c|c|}
\hline & Mother (25) & Immediately after birth(25) & p-value (Mc Nemar Test) \\
\hline Sterile & 0 & 19 & NA \\
\hline Staphylococcus epidermidis & 22 & 6 & $<\mathbf{0 0 1}$ \\
\hline Staphylococcus aureus & 3 & 0 & 0.250 \\
\hline Streptococcus salivarius & - & - & NA \\
\hline Lactobacillus & 16 & 0 & <0.001 \\
\hline Klebsiella sp. & - & - & 0.031 \\
\hline Neisseria sp. & 6 & 0 & NA \\
\hline Pseudomonas aeroginosa & - & - & 0.016 \\
\hline Candida albicans & 9 & 2 & 0.500 \\
\hline Gardnerella sp. & 2 & 0 & 0.500 \\
\hline E. coli & 2 & 0 & 0.500 \\
\hline
\end{tabular}

Table IV:- Intra group comparison of microbial load in oral cavity of newborn through Caesarean delivery

\begin{tabular}{|l|l|l|l|}
\hline Bacteria & Immediately after birth(25) & $\begin{array}{l}\mathbf{2} \text { Hours after } \\
\text { feeding(25) }\end{array}$ & $\begin{array}{l}\text { Immediate v/s After 2 } \\
\text { hrs }\end{array}$ \\
\hline Sterile & 19 & 3 & $<0.001$ \\
\hline $\begin{array}{l}\text { Staphylococcus } \\
\text { epidermidis }\end{array}$ & 6 & 19 & $<0.001$ \\
\hline Staphylococcus aureus & - & - & NA \\
\hline Streptococcus salivarius & - & 7 & NA \\
\hline Lactobacillus & - & 4 & NA \\
\hline Klebsiella sp. & - & - & NA \\
\hline Neisseria sp. & - & - & NA \\
\hline Pseudomonas aeroginosa & - & - & NA \\
\hline Candida albicans & 2 & 2 & 1.000 \\
\hline Gardnerella sp. & - & - & NA \\
\hline E. coli & - & - & NA \\
\hline Micrococcus & - & - & NA \\
\hline
\end{tabular}


Table V:- Intergroup comparison of the levels of micro organisms in the oral cavity of newborn immediately after delivery

\begin{tabular}{|c|c|c|c|}
\hline Bacteria & Normal delivery (25) & Caesarean delivery (25) & $\begin{array}{c}\text { P-value (pearson's } \\
\text { chi-square test) }\end{array}$ \\
\hline Sterile & 10 & 19 & 0.021 \\
\hline Staphylococcus epidermidis & 15 & 6 & 0.021 \\
\hline Staphylococcus aureus & - & - & NA \\
\hline Streptococcus salivarius & - & - & NA \\
\hline Lactobacillus & 6 & 0 & 0.022 \\
\hline Klebsiella sp. & 7 & 0 & 0.010 \\
\hline Neisseria sp. & 9 & 0 & $\mathbf{0 . 0 0 2}$ \\
\hline Pseudomonas aeroginosa & 2 & 0 & 0.490 \\
\hline Candida albicans & 4 & 2 & 0.667 \\
\hline Gardnerella sp. & 6 & 0 & 0.022 \\
\hline E. coli & 4 & 0 & 0.110 \\
\hline Micrococcus & 1 & 0 & 1.000 \\
\hline
\end{tabular}

Table VI:- Intergroup comparison of the levels of micro organisms in the oral cavity of newborn immediately after delivery.

\begin{tabular}{|l|l|l|l|}
\hline Bacteria & $\begin{array}{l}\text { NORMAL } \\
\text { DELIVERY }\end{array}$ & $\begin{array}{l}\text { CAESAREAN } \\
\text { DELIVERY }\end{array}$ & $\begin{array}{l}\text { p-value (Pearson's Chi- } \\
\text { square test) }\end{array}$ \\
\hline Sterile & 2 & 3 & 1.000 \\
\hline Staphylococcus Epidermidis & 21 & 19 & 0.725 \\
\hline Staphylococcus Aureus & - & - & NA \\
\hline Streptococcus Salivarius & 6 & 7 & 1.000 \\
\hline Lactobacillus & 9 & 4 & 0.196 \\
\hline Klebsiella sp. & 3 & 0 & 0.235 \\
\hline Neisseria sp. & 4 & 0 & 0.110 \\
\hline Pseudomonas Aeroginosa & - & - & NA \\
\hline Candida albicans & 1 & 2 & 1.000 \\
\hline Gardnerella sp. & - & - & NA \\
\hline E. coli & - & 0 & 1.000 \\
\hline Micrococcus & - & - & NA \\
\hline
\end{tabular}

Funding: None

Conflict of Interests: None

\section{Acknowledgements:-}

Special thanks to Dr. Sharad Yadav, Dr. Amit Kumar Balyan, Dr. Rakesh Mehta and Dr. Geeta Mehta for their kind support and help in completing this research work.

\section{References:-}

1. Josef Neu and Jona Rushing: Cesarean versus Vaginal Delivery: Long term infant outcomes and the Hygiene Hypothesis. Clin Perinatol. 2011 June ; 38(2): 321-331.

2. Hegde S, Munshi A.K: Influence of the maternal vaginal microbiota on the oral microbiota of the newborn. J of Clin Pedi Dent; 1998; 22(4): 317-321.

3. Jean M Ross, J R Needham: Genital flora during pregnancy and colonization of the newborn. Journal ofthe Royal Society of Medicine Volume 73 February 1980.

4. Bourgeois-Nicolaos N, Lucet JC, Daubié C, Benchaba F, Rajguru M, Ruimy R, Andremont A, Armand-Lefèvre L. Maternal vaginal colonisation by Staphylococcus aureus and newborn acquisition at delivery. Paediatr Perinat EpidemioL. 2010 Sep;24(5):488-91.

5. P. Lif Holgerson, L. Harnevik, O. Hernell, A.C.R. Tanner , and I. Johansson. Mode of Birth Delivery Affects Oral Microbiota in Infants. J Dent Res. 2011 Oct; 90(10): 1183-1188. 
6. Maya Rashkova, Nina Toneva, Marieta Belcheva, Milena Peneva: Oral colonisation with Candida of newborn children: risk factors associated with pregnancy and delivery. OHDMBSC -8(4) - December, 2008

7. Witkowski R: Aerobe mundhohlenflora bei mutter and kind. Zentralbl. Baktetiol. Parasitenk. Infektionskr Hyg. Abt. I 1935; 133:334.

8. Panesar J, Munshi A.K: Comparison of the oral microbiota between the normal and ceasarean delivered neonates. J Indian Soc Prev Dent; 1997; 15(2):49-54.

9. $\quad S$ D. P., S V.V., S N.D. Comparison Of Oral Microbiota In Various Modes During Births Viz., Normal, Induced, Episiotomy, Forceps, Cesarean And Premature Neonates The Internet Journal of Dental Science. 2010. 10(1).

10. Torres Alipi B.I, Fragoso Ramirez J.A: Bacterial colonization of the oral cavity in newborn. Bol Med Hosp Infant Mex; 1990; 47(2): 78-83.

11. Maria G. Dominguez-Bello, Elizabeth K. Costello, Monica Contreras, Magda Magris, Glida Hidalgo, Noah Fierer, Rob Knight: Delivery mode shapes the acquisition and structure of the initial microbiota across multiple body habitats in newborns. Proc Natl Acad Sci U S A 2010; 107(26):11971-5.

12. Mandar R, Mikelsaar M: Transmission of mother's microflora to the newborn at birth. Biol Neonate; 1996; 69(1):30-35. 